\title{
SOFTWARES EDUCATIVOS: Uma Proposta de Recurso Pedagógico para o Trabalho de Reforço das Habilidades de Leitura e Escrita com Alunos dos Anos Iniciais *
}

PEREIRA, Lisandra Locatelli - Professora dos Anos Iniciais na Rede Pública Venâncio Aires; Especializanda em Tecnologias da Informação e da Comunicação Aplicadas a Educação - UFSM/EAD -

lisandralocatellip@hotmail.com

CORDENONSI, André Zanki - Professor do Departamento de Documentação, do Centro de Ciências Sociais e Humanas- UFSM -Atua nas áreas de Informática na Educação, Sistemas de Informação e Documentação e Inteligência Artificial andrezc@inf.ufsm.br

Resumo: Este artigo trata do uso de tecnologias digitais em atividades didáticas de reforço escolar com alunos dos anos iniciais, que estão em processo de alfabetização. A importância dos materiais educativos digitais e das práticas pedagógicas inovadoras surge como meios para potencializar o processo das habilidades de leitura e escrita. As tecnologias de informação e comunicação - TICs trazem contribuições à produção escrita e à leitura prazerosa apontando novos horizontes para a formação de uma sociedade de leitores e escritores. Por tratar-se de uma nova forma de expressão do pensamento e interação, a incorporação desses recursos à educação é objeto de investigação principalmente pelos avanços dos processos cognitivos que suscitam.

Palavras-chave: Softwares Educativos; Reforço; Habilidades de leitura e escrita

Abstract: This paper discusses the use of digital technologies to enhance educational activities with school students of the early years, who are learning to read. The importance of digital educational materials and teaching practices comes as means to enhance the process skills of reading and writing. Information technology and communication - ICT bring contributions to the writing and reading pleasure pointing out new horizons for the formation of a society of readers and writers. As this is a new form of expression of thought and interaction, the incorporation of these resources to education is under investigation mainly by advances in cognitive processes they generate.

Keywords: Educational Software; Tutoring; Writing-Reading Skills

\footnotetext{
* Trabalho de conclusão do Curso de Especialização em Tecnologias da Informação e da Comunicação Aplicadas à Educação - EAD - Universidade Federal de Santa Maria - UFSM Projeto Universidade Aberta do Brasil - UAB
} 


\section{INTRODUÇÃO}

A informática está presente de maneira irreversível na nossa vida atualmente. As mudanças que vem ocorrendo na sociedade, principalmente decorrente das novas descobertas e inovações tecnológicas vêm exigindo uma reorganização nas atividades escolares, uma educação de qualidade e um professor preparado para enfrentar desafios e propor soluções. Portanto, é fundamental refletir sobre a aplicação de recursos informatizados na educação.

As tecnologias digitais vêm mostrando que é possível o desenvolvimento de um novo paradigma educacional. Para isso, se faz necessário o desenvolvimento de sistemas que atendam os diferentes tipos de pessoas participantes da sociedade. As tecnologias da informação e da comunicação aplicadas à educação, com uma proposta construcionista, podem ser utilizadas no processo de ensino e de aprendizagem, enquanto ferramentas para o desenvolvimento de aspectos cognitivos e sociais de qualquer pessoa.

$\mathrm{O}$ ato de ler e de escrever é um processo cognitivo, mas a busca por seu desenvolvimento depende, muitas vezes, de como ele acontece. Devemos enquanto professores procurar maneiras, caminhos alternativos, que possibilitem o aprendizado da leitura e da escrita, respeitando o tempo de cada aluno, fazendo com que ele supere a sua própria limitação. Nesse sentido, pensamos de que forma os softwares educativos podem auxiliar nas atividades de reforço das habilidades de leitura e escrita dos alunos em fase de alfabetização?

Este trabalho tem como objetivo principal integrar os softwares educativos como forma de potencializar a conquista de habilidades referentes a leitura e a escrita de alunos que se estão em processo de alfabetização. Este estudo trata de uma investigação a respeito do uso de softwares educativos e se estes contribuem na aprendizagem de alunos dos anos iniciais do Ensino Fundamental. A análise transcorrerá em uma escola do interior da rede pública de ensino da cidade de Venâncio Aires, rede esta que tem disponível equipamentos na área tecnológico educacional. Para alcançar os objetivos desta pesquisa, serão realizados encontros semanais no laboratório de informática com os alunos da classe do $2^{\circ}$ ano, utilizando softwares educativos.

Neste sentido, o computador pode ser um grande aliado no processo de desenvolvimento cognitivo, pois os recursos audiovisuais provocam o aluno a querer saber mais sobre a informação que está visualizando. A ferramenta envolve-o por meio da variação de cores, movimento, imagens, que chamam a atenção do mesmo para novas leituras. Para Conforto (2007), os ambientes computacionais oportunizam o entrelaçamento de texto, som e imagem numa mesma publicação, colocando o processo de construção na mão de sujeitos em processo de aprendizagem.

Essas atividades de leitura e de escrita proporcionam novo meio ou maneira do aluno se expressar e de se relacionar, pois transmite várias informações, as quais possibilitam ao mesmo melhorar sua comunicação. Isto favorece também, para o desenvolvimento de novas habilidades do uso da máquina, que o levam a novas aprendizagens, as quais proporcionam diferentes formas de pensar e aprender. 


\section{TICS NA EDUCAÇÃO}

As Tecnologias de Informação e Comunicação (TICs) vêm causando um impacto significativo no processo de ensino-aprendizagem, apresentando novas perspectivas de acesso ao conhecimento universal e possibilitando outras maneiras de produzi-los através da constituição de redes de comunicação. $\mathrm{O}$ acesso à tecnologia expandiu o espaço da sala de aula para além de suas paredes físicas, levando professores e alunos a mergulharem em novos conhecimentos bem mais diversificados e atualizados, proporcionando o letramento e a inclusão digital.

Estudos e investigações, em âmbito nacional e internacional, revelam a importância e o potencial que as TICs assumem no campo da Educação. A utilização desses novos recursos em todos os níveis da educação modifica a dinâmica do ensino, as estratégias e o comprometimento de alunos e professores. Com essas novas ferramentas a educação pode oportunizar uma aprendizagem significativa, proporcionando que o aluno aprenda de forma dinâmica e motivadora.

No entanto, as TICs, por si só, não desempenham as funções esperadas se não forem mediadas por professores capacitados. Assim, tem-se enfatizado o fato de o professor de sala de aula, ter conhecimento dos potenciais educacionais da informática, criando, assim, condições para os alunos construírem seu conhecimento, ao mesmo tempo em que proporciona sua inclusão digital e social. De acordo com Valente (2001), a informática na educação enfatiza a necessidade de o professor ter o conhecimento das potencialidades educacionais do computador para assim poder mesclar atividades de ensino e aprendizagem informatizadas e não informatizadas.

Atualmente não se pode mais pensar numa sociedade onde recursos de informática não estejam presentes, todavia, é importante ressaltar a idéia de que o uso de recursos tecnológicos, não pode ser feito sem um conhecimento prévio dos mesmos e que esse conhecimento deve sempre estar atrelado a princípios teórico-metodológicos claros e bem fundamentado. Daí a importância dos professores terem conhecimentos das tecnologias educacionais e fazerem uma análise cuidadosa e criteriosa dos materiais a serem utilizados, tendo em vista os objetivos que se quer alcançar.

Sabe-se que o emprego deste ou daquele recurso tecnológico de forma isolada não é garantia de melhoria da qualidade da educação. A conjunção de diversos fatores e a inserção da tecnologia no processo pedagógico da escola e do sistema é que favorecem um processo de ensino-aprendizagem de qualidade. (Guia de Tecnologias Educacionais 2009, p.17)

Assim as Tecnologias da Informação e Educação - TICs assumem cada vez mais um papel de destaque na sociedade, pois estão inseridas na maioria das atividades realizadas atualmente, se fazendo presente na comunicação entre as pessoas. Dessa forma, a inclusão digital na escola incorpora diferentes práticas pedagógicas, novas relações sociais, novos olhares sobre o significado do processo de ensino e aprendizagem. Os recursos tecnológicos usados na Educação devem caminhar buscando um objetivo único: potencializar o processo de ensino e aprendizagem. A inclusão das tecnologias de informação e comunicação no ambiente escolar não deve se limitar à mera informatização da escola, mas propiciar a reflexão dos papéis dos sujeitos envolvidos e 
uma nova postura em relação ao conhecimento. Essa mudança paradigmática exige uma nova postura educacional, em que a participação e a análise crítica permeiem todo o processo ensino-aprendizagem. De acordo com (Valente 1997, p. 3):

O mundo atualmente exige um profissional crítico, criativo, com capacidade de pensar, de aprender a aprender, de trabalhar em grupo e de conhecer o seu potencial intelectual, com capacidade de constante aprimoramento e depuração de idéias e ações.

Todos esses materiais educativos para cumprirem com o objetivo de recurso didático precisam ser utilizados por professores que saibam explorar as potencialidades do mesmo, selecionando as atividades específicas para cada fase de aprendizagem e possibilitando ao aluno trabalhar através da descoberta. $\mathrm{O}$ computador é um recurso cuja eficácia depende daqueles que o usam, daí ser necessário que o professor esteja capacitado e que haja mudanças nas práticas pedagógicas.

Essa discussão se faz necessária à medida que as TIC passam a fazer parte do dia-a-dia na escola e na vida do professor. A utilização correta de softwares e a navegação na internet, por meio de e-mail, sites de pesquisa etc., se tornam competências e conhecimentos importantes para professores e alunos, em razão da grande necessidade exigida pela sociedade como um todo. O Guia de Tecnologias Educacionais declara que:

Embora se considere importante o uso de uma tecnologia, vale lembrar que esse uso se torna desprovido de sentido se não estiver aliado a uma perspectiva educacional comprometida com o desenvolvimento humano, com a formação de cidadãos, com a gestão democrática, com o respeito à profissão do professor e com a qualidade social da educação. (2009 p.16)

A introdução das Tecnologias de Informação e Comunicação (TIC) na escola é um fenômeno que oferece uma variedade de atividades inovadoras que requerem mudanças no contexto escolar, como a formação, o envolvimento e o compromisso de toda a comunidade envolvida no processo educacional, buscando articular o conhecimento e favorecendo o desenvolvimento do processo de ensino e aprendizagem do aluno.

Desse modo, apoiado pelas exigências para o uso das TICs, o processo educacional deve repensar o processo de ensino e aprendizagem para que o aluno saiba lidar com as inovações tecnológicas, pois, o uso destes recursos na escola, contribui para a expansão do acesso à informação, à comunicação e do estabelecimento de novas relações com o saber, que ultrapassam os limites da escola, alcançando outros espaços produtores de conhecimento. "Essa mudança implica em uma alteração de postura dos profissionais em geral e, portanto, requer o repensar dos processos educacionais" (Valente 1997, p. $5)$.

O fascínio que as atividades informatizadas promovem no cotidiano infantil leva as crianças realizarem as mesmas de forma lúdica, pois podem jogar, criar, aprender e comunicar-se com prazer e criatividade. Dessa forma, o computador enquanto elemento lúdico propicia à criança a expressão de seus pensamentos, de situações imaginárias e de suas próprias relações sociais, pois ao brincar, o real e o criativo interagem continuamente, não existindo entre eles contradições, mas afinidades que permitem a sua contínua inter-relação.

V. $7 \mathrm{~N}^{\mathrm{o}}$ 3, dezembro, 2009 
Acreditamos que o momento ideal para o início do contato com esses instrumentos é a partir da educação infantil, pois as iniciativas de inclusão digital por meio do uso das TICs contribuem significativamente com a aprendizagem dos alunos. As histórias infantis digitais também representam um material didático rico, com funções cognitivas, que auxiliam na construção do conhecimento. Elas são intrinsecamente motivadoras, normalmente, baseadas em fatores sociais e culturais, todos relacionados ao ato de brincar e imitar com características de fantasia, de desafios e de curiosidade.

Relacionado ao uso das TICs nas atividades pedagógicas, é importante observar algumas concepções subjacentes em diversos softwares educativos destinados ao processo de alfabetização da criança tanto na educação infantil quanto nos primeiros anos do ensino fundamental. Com uma linguagem visual dinâmica e agradável, muitos softwares emanam concepções tradicionais de ensino e conduzem a uma atitude passiva do educando. Outros já valorizam a interação através da realização de tarefas, de resolução de problemas, de desenhos e escrita. Teberosky e Colomer (2003), apud Silva (2006, p.159), enfatizam que: “ [...] a participação nas práticas junto ao computador cria um novo tipo de leitura e uma nova escrita, que se distanciam em alguns aspectos das mesmas atividades realizadas em suportes de papel".

Inserido em sala de aula, o computador deve servir como uma ferramenta inovadora, que pode efetivamente contribuir para um avanço qualitativo no processo de ensinoaprendizagem. $\mathrm{O}$ computador pode constituir-se como um recurso que vai além do quadro e dos livros didáticos, dada sua grande disponibilidade atual. Valente (1997, p.3) em suas palavras declara que:

[...] os sistemas computacionais apresentam hoje diversos recursos de multimídia, como cores, animação e som, possibilitando a apresentação da informação de um modo que jamais o professor tradicional poderá fazer com giz e quadro negro mesmo que ele use o giz colorido e seja um exímio comunicador.

Atualmente, observa-se nas escolas uma ampla exploração da Internet, de programas específicos de edição de textos e imagens e de softwares educativos. Cabe ao educador analisar criteriosamente os recursos da informática que pretende utilizar em suas aulas, verificando seus aspectos técnicos e sua pertinência pedagógica, ou seja, sua funcionalidade dentro dos conteúdos inicialmente previstos. Conforme SILVA (2006, p. 153):

Quanto aos softwares educacionais, é necessário que sejam escolhidos em função dos objetivos visados no processo de ensino e aprendizagem, distinguindo-se os que objetivam testar conhecimentos dos que procuram levar o aluno a interagir com o programa de forma a construir conhecimento.

Os jogos interativos na Web não são apenas para brincadeira. Com a grande aceitação da Internet, atualmente muitos professores estão usando jogos baseados na Web como uma forma de empregar, simular, educar e assessorar. A utilização desses novos recursos modifica a dinâmica do ensino, as estratégias e o comprometimento de alunos e professores. Com esses novos recursos e ferramentas a educação pode oportunizar uma aprendizagem significativa, proporcionando que o aluno aprenda de forma dinâmica e motivadora.

V. $7 \mathrm{~N}^{\mathrm{o}}$ 3, dezembro, 2009 


\section{ESTUDO DE CASO}

A informática constitui um atrativo na aprendizagem. Não encontramos criança que apresente resistência ao enfrentamento do desconhecido em informática. Esta questão se potencializa se considerarmos a representatividade que a informática tem para crianças e adolescentes. Como mais um recurso para interagir com a língua materna, instância fundamental do aprender, a informática constitui uma fonte rica para a apropriação e desenvolvimento do processo de construção da língua escrita.

Este trabalho orientou-se então, pela necessidade de investigar as possibilidades pedagógicas do uso de softwares educativos com alunos dos anos iniciais que estão em processo de alfabetização. Com uma abordagem qualitativa e possuindo um caráter de estudo de campo, os dados foram obtidos através de aplicações com encontros presenciais com alunos, observações, conversas e análise dos níveis de aprendizagem dos alunos.

O uso de softwares educativos em alfabetização tem se mostrado como eficazes na apropriação da leitura e escrita. Os softwares voltados a alunos que estão em processo de aquisição da leitura e escrita, levam o sujeito a estabelecer relações, pensar, levantar e confrontar hipóteses, principalmente frente ao erro, ocasião em que o jogo é interrompido na tentativa de saber o que aconteceu e/ou resolver o impasse, oportunizando a interação. Teberosky em uma entrevista para a revista Nova Escola (2005) coloca que:

O micro permite aprendizados interessantes. No teclado, por exemplo, estão todas as letras e símbolos que a língua oferece. Quando se ensina letra por letra, a criança acha que o alfabeto é infinito, porque aprende uma de cada vez. Com o teclado, ela tem noção de que as letras são poucas e finitas. Nas teclas elas são maiúsculas e, no monitor, minúsculas, o que obriga a realização de uma correspondência. Além disso, quando está no computador o estudante escreve com as duas mãos. Os recursos tecnológicos, no entanto, não substituem o texto manuscrito durante o processo de alfabetização, mas com certeza o complementam.

Com a LDB 9.394/96, uma série de ações, inseridas em um novo contexto para o ensino público, vêm tentando sistematizar e legitimar propostas voltadas à superação do fracasso escolar. Entre elas, os estudos de recuperação e reforço, que parecem emergidos numa perspectiva que demonstra uma maior preocupação com a qualidade da aprendizagem.

$\mathrm{Na}$ tentativa de alcançar um resultado qualitativo na aprendizagem dos alunos da turma do $2^{\circ}$ ano do Ensino Fundamental que, ainda não se apropriaram da escrita e da leitura de forma autônoma, procurou-se oportunizar atividades de reforço mediadas pelas tecnologias da informação e da comunicação. Conforme o artigo 24, alínea "e" da LDB 9.394/96:

Artigo 24. A educação básica, nos níveis fundamental e médio, será organizada de acordo com as seguintes regras comuns:

$[\ldots]$

V. $7 \mathrm{~N}^{\mathrm{o}}$ 3, dezembro, 2009 
V - a verificação do rendimento escolar observará os seguintes critérios:

[...]

e)obrigatoriedade de estudos de recuperação, de preferência paralelos ao período letivo, para os casos de baixo rendimento escolar, a serem disciplinados pelas instituições de ensino em seus regimentos;

Importante salientar que através do planejamento, o uso da informática e dos softwares educativos pode vir a apresentar resultados significativos no processo de aquisição ou construção do conhecimento, proporcionando, assim, condições cognitivas para o desenvolvimento da autonomia do aluno. Quando se trata das possibilidades do uso de softwares educativos, os mais utilizados são os jogos multimídias, a programação pedagógica e em alguns casos a Internet. Ou seja, existe uma diversidade de softwares que podem ser utilizados no processo aprendizagem, desde que sejam considerados os objetivos pedagógicos. Para que o professor possa propor boas situações de aprendizagem utilizando os computadores, é fundamental conhecer os softwares que se pretende utilizar para problematizar conteúdos curriculares. "Segundo Ferreiro (2000) as crianças são facilmente alfabetizáveis, desde que descubram, através de contextos sociais funcionais, que a escrita é um objeto interessante que merece ser conhecido.

A fim de responder o objetivo proposto, que é integrar os softwares educativos como forma de potencializar a conquista de habilidades referentes a leitura e escrita com atividades de reforço para alunos que se estão em processo de alfabetização, o trabalho foi desenvolvido em uma escola do interior da rede municipal de ensino do município de Venâncio Aires. Os sujeitos da pesquisa foram os alunos da turma do $2^{\circ}$ ano do Ensino Fundamental. Como o trabalho volta-se ao estudo do uso de softwares educativos no trabalho de reforço das habilidades de leitura e escrita, somente três alunos participarão das atividades no laboratório de informática da escola, pois estes ainda não se encontram na fase alfabética do sistema da leitura e escrita. Dessa forma, compreendemos que o uso de softwares voltados a esta fase serão fundamentais para o trabalho de reforço, proporcionando ao aluno, como ao professor novas formas de aprender, como também de ensinar.

Para uma melhor compreensão a respeito dos níveis da alfabetização faz-se necessário abordarmos o que as pesquisadoras, Ferreiro e Teberoski (1991) tratam sobre o processo da lecto-escrita da criança. Por acreditarem que a criança busca a aprendizagem na medida em que constrói o raciocínio lógico e que o processo evolutivo de aprender a ler e escrever passa por níveis de conceitualização que revelam às hipóteses a que chegou a criança. As autoras definiram, em sua obra Psicogênese da Língua Escrita, cinco níveis. A caracterização de cada nível não é determinante, podendo a criança estar em um nível ainda com características do nível anterior. Essas situações são mais freqüentes nos níveis Intermediários I e II, onde freqüentemente podemos nos deparar com contradições na conduta da criança e nos quais se percebe a perda de estabilidade do nível anterior e a não estabilidade no nível seguinte, evidenciando o conflito cognitivo.

$\mathrm{Na}$ primeira fase, início dessa construção, hipótese pré-silábica, as tentativas das crianças dão-se no sentido da reprodução dos traços básicos da escrita com que elas se deparam no cotidiano. O que vale é a intenção, pois, embora o traçado seja semelhante, cada um lê em seus rabiscos aquilo que quis escrever. Desta maneira, cada um só pode interpretar a sua própria escrita, e não a dos outros. Nesta fase, a criança elabora a 
hipótese de que a escrita dos nomes é proporcional ao tamanho do objeto ou ser a que está se referindo.

Na fase dois, a hipótese central é de que para ler coisas diferentes é preciso usar formas diferentes. A criança procura combinar de várias maneiras as poucas formas de letras que é capaz de reproduzir. Nesta fase, ao tentar escrever, a criança respeita duas exigências básicas: a quantidade de letras (nunca inferior a três) e a variedade entre elas, (não podem ser repetidas).

$\mathrm{Na}$ terceira fase, são feitas tentativas de dar um valor sonoro a cada uma das letras que compõem a palavra. Surge a chamada hipótese silábica, isto é, cada grafia traçada corresponde a uma sílaba pronunciada, podendo ser usadas letras ou outro tipo de grafia. Há, neste momento, um conflito entre a hipótese silábica e a quantidade mínima de letras exigida para que a escrita possa ser lida. A criança, neste nível, trabalhando com a hipótese silábica, precisa usar duas formas gráficas para escrever palavras com duas sílabas, o que vai de encontro às suas idéias iniciais de que são necessários pelo menos três caracteres. Este conflito a faz caminhar para outra fase.

$\mathrm{Na}$ fase quatro ocorre então a transição da hipótese silábica para a alfabética. O conflito que se estabeleceu - entre uma exigência interna da própria criança (o número mínimo de grafias) e a realidade das formas que o meio lhe oferece, faz com que ela procure soluções. Ela, então, começa a perceber que escrever é representar progressivamente as partes sonoras das palavras, ainda que não o faça corretamente.

$\mathrm{Na}$ fase cinco, finalmente, é atingido o estágio da escrita alfabética, pela compreensão de que cada um dos caracteres da escrita corresponde valores menores que a sílaba, e que uma palavra, se tiver duas sílabas, exigindo, portanto, dois movimentos para ser pronunciada necessitarão mais do que duas letras para ser escrita e a existência de uma regra produtiva que lhes permite, a partir desses elementos simples, formarem a representação de inúmeras sílabas, mesmo aquelas sobre as quais não se tenham exercitado.

Ainda, relacionado a temática da alfabetização uma das metas do Plano de Desenvolvimento da Educação (PDE), é que todas as crianças saibam ler e escrever até os oito anos de idade, ou seja que tenham alcançado o nível alfabético da leitura e escrita. Sendo assim, entende-se a necessidade de proporcionar atividades de reforço como coloca a LDB 9.394/96 para os alunos que ainda não se encontram no nível alfabético. Dessa forma, reconhecemos que os meios informatizados são ferramentas poderosas para auxiliar, em especial no processo de alfabetização, principalmente quando as atividades digitais dispõem de recursos multimídia. Relacionado a este assunto, Prieto et al (2005, p.6) afirmam que:

A multimídia é a combinação de texto, som, imagem, animação e vídeo, ou seja, incorpora todas as mídias existentes para representar uma informação. É, por isso, uma forma poderosa de comunicação, pois ganha e mantém a atenção e o interesse do aluno e com isto promove a retenção da informação. Para a Educação, uma atividade didática multimídia bem empregada, é um recurso poderoso, pois, estimula todos os sentidos e pode oferecer uma experiência melhor que qualquer outra mídia sozinha. 
Tendo por base que o Software Educativo é uma das principais tecnologias que se conhece para o auxílio na aprendizagem através do uso do computador e, que atualmente, está mais difícil prender a atenção dos alunos com as aulas tradicionais, as novas tecnologias da comunicação vêm transformar as maneiras de como ensinar e de como aprender. Com isso, destaca-se a importância e a necessidade da inclusão de metodologias de ensino, como a apresentada que façam uso desse recurso. Os Parâmetros Curriculares Nacionais (PCN 1997) em sua parte introdutória enfatiza a necessidade de se utilizar computadores como ferramenta auxiliar no processo de aprendizagem dos alunos nas distintas disciplinas.

\section{ANÁLISE E DISCUSSÃO}

Os resultados revelaram a contribuição efetiva dos softwares como ferramentas com potencial lúdico e didático capaz de garantir a motivação do aluno e uma aprendizagem significativa.

Os dados desta pesquisa foram coletados no decorrer do $2^{\circ}$ trimestre letivo de 2009. Foram realizadas 10 sessões de aplicação e observação das atividades de cada aluno de forma individual na sala de informática, que ocorriam uma ou duas vezes na semana. Os registros foram feitos por escrito, manualmente, em caderno especialmente preparado. O objetivo principal dessas sessões foi verificar como os softwares educativos podem auxiliar no processo de alfabetização de alunos dos anos iniciais da classe regular de ensino, que necessitam de reforço escolar.

As atividades de reforço foram realizadas no laboratório de informática da escola, em contra turno ao horário das aulas. Os alunos foram atendidos pela professora regente de forma individual, uma ou duas vezes por semana. A escolha por atendimento individual deriva-se pelo fato de estar interagindo de forma mais específica com cada aluno, pois o professor tem um papel importante, a tarefa de problematizar situações possibilitando aos alunos momentos de reflexão e discussão. Ao intervir e oportunizar a construção de hipóteses amplia-se a leitura de mundo do aluno durante o processo da aprendizagem.

A interação aluno computador precisa ser mediada por um profissional que tenha conhecimento do significado do processo de aprendizado através da construção do conhecimento, que entenda profundamente sobre o conteúdo que está sendo trabalhado pelo aluno e que compreenda os potenciais do computador. Esses conhecimentos precisam ser utilizados pelo professor para interpretar as idéias do aluno e para intervir apropriadamente na situação de modo a contribuir no processo de construção de conhecimento por parte do aluno. (Valente 1997, p. 4).

Para a realização das atividades de reforço no laboratório de informática, foram selecionados alguns softwares educativos, tais como: Menino Curioso, Tux Paint e atividades do site Atividades Educativas, ambos voltados para o processo de alfabetização.

O software Menino Curioso possui atividades e é destinado a crianças em fase de Alfabetização, apresentando letras e algarismos através de jogos didáticos, para a formação de palavras e a exploração de conceitos matemáticos, segundo as V. $7 \mathrm{~N}^{\circ}$ 3, dezembro, 2009 
especificações do produto. Trabalha através do processo lúdico, as diversas fases do processo de alfabetização. O Tux Paint é um software livre que oferece suporte a som e animação em diálogo. É um programa que pode ser usado para crianças dos três aos 12 anos, tem uma interface simples e é de fácil utilização, com efeitos sonoros divertidos em cada ferramenta e um mascote que guia as crianças na utilização do programa. Apresenta uma série de recursos de desenho que impulsionam a criatividade e imaginação das crianças. Permitem desenhar, colorir, construir formas, ambientes conhecidos, são muito bem aceitos e tem grande valor educativo e alta capacidade de entretenimento. $\mathrm{O}$ site Atividades Educativas, é um espaço que contém várias atividades específicas dentro de cada área do ensino. As atividades são variadas desde jogos, histórias animadas, simulações, que podem ser vistas e realizadas diretamente na Web, com recurso multimídia (texto, imagem, áudio, animação), o que se torna atrativo para as crianças. Este site contém um link exclusivo com atividades de alfabetização.

A participação dos alunos no laboratório, seguiu de forma pré-estabelecida pela professora, no intuito de estabelecer atividades dirigidas de acordo com a necessidade de cada aluno, ou seja, trabalhos voltados especificamente para o nível de aprendizagem de cada um dos alunos. "[...] o uso inteligente do computador não é um atributo inerente ao mesmo mas está vinculado a maneira como nós concebemos a tarefa na qual ele será utilizado" (Valente1997, p.1).

Esta forma diferenciada de reforço teve um resultado excelente. A assiduidade e o interesse dos alunos foram visíveis, e puderam ser constatados pelos resultados na aprendizagem dos alunos. As atividades de reforço passaram a ser a oportunidade de mexer no computador e aprender os conteúdos de forma diferenciada. Todos gostam e aprendem a usar os recursos dos diferentes programas com relativa facilidade e autonomia. Soma-se ainda ao final de cada jogo, o que a animação registra sobre o desempenho, a leitura do resultado, as possibilidades e a tomada de decisão para o procedimento seguinte. Nesse momento o sorriso é emergente demonstrando que o aluno realizou as atividades com êxito.

A utilização de um software no computador por um aluno pode desencadear novos conflitos cognitivos. Estes conflitos ocorrem não pelas ferramentas em si, mas pela interação deste sujeito com elas e porque existirá a interferência de outro indivíduo (professor) que poderá atuar como promotor do crescimento cognitivo do aluno.

Após todas as 10 sessões, o que se torna mais especial, surpreendente e gratificante de todo o trabalho, é o fato de presenciar o crescimento na aprendizagem dos três alunos que participaram das atividades de reforço através da informática. Ambos alcançaram novos níveis no processo de alfabetização. Sabemos a partir dos estudos de Ferreiro (2000) que a criança elabora hipóteses sobre a escrita, assim as atividades devem desafiar o pensamento das crianças e gerar conflitos cognitivos que os ajudem a buscar novas respostas. Dessa forma, buscou-se durante a realização das aulas de reforço propor atividades direcionadas, observando o nível em cada aluno se encontrava.

Para o ALUNO-A que estava no nível pré-silábico procurou-se atividades com as letras do alfabeto e números. O resultado do trabalho realizado com este aluno foi um dos mais gratificantes, no sentido de que havia uma preocupação com o processo de aprendizagem do mesmo, por encontrar-se no nível pré-silábico, enquanto os demais colegas já estavam alfabetizados ou em etapas mais avançadas ao seu nível. A superação do nível pré-silábico para o nível Intermediário, entre pré-silábico e silábico,

V. 7 No 3, dezembro, 2009 
foi uma conquista muito importante. Como destacamos durante o trabalho não temos a pretensão de que os alunos ao final das atividades estivessem no nível alfabético, no entanto ressaltamos esta conquista nas habilidades da leitura e escrita.

O ALUNO-B que se encontrava no nível silábico, encontra-se no nível silábicoalfabético, que é uma etapa intermediária entre silábico e alfabético. O trabalho com este aluno foi muito satisfatório, pois o mesmo alcançou um nível de aprendizagem elevado, no entanto o trabalho continua.

No trabalho com o ALUNO-C que se encontrava no silábico-alfabético, realizou-se atividades que favorecessem o avanço para a próxima etapa da leitura e escrita, que é a alfabética. $\mathrm{O}$ trabalho com este aluno foi muito gratificante, pois o mesmo alcançou o nível alfabético do processo de alfabetização.

O que há de especial neste trabalho é que as TICs proporcionam ao professor, como ao aluno, novas formas de ensinar e de aprender. O educador deixa de ser um passador de matéria no quadro e vira um mediador-estimulador do aluno, a criança por sua vez, usufrui de atividades diferenciadas, atrativas, com movimentos, com cores, estimulando os sentidos, o raciocínio, as hipóteses de leitura e escrita, etc. Dessa forma fica evidenciado o quanto as tecnologias educacionais podem contribuir para o sucesso ou êxito do processo de ensino/aprendizagem.

\section{CONCLUSÃO}

São múltiplos os indícios apresentados por este estudo de que a introdução das TICs na prática escolar, quando mediada pelo trabalho reflexivo do professor com experiência no uso da informática, pode efetivamente desencadear um processo de mudança da cultura docente e da cultura escolar.

O contexto atual exige a inserção das TIC em diversos âmbitos da sociedade. A escola, desde as etapas iniciais deve contemplar esta exigência. Entretanto, para dar sentido à inserção das tecnologias nas instituições educativas, se deve passar por um processo de formulação de objetivos e preparação dos docentes. Além disso, é de extrema importância que se reflita sobre os diversos elementos que podem influenciar no seu sucesso ou fracasso.

O contato com softwares educativos voltados ao processo de alfabetização trouxe uma extraordinária riqueza de informações composta de sistema multimídia que foram acessados de uma maneira dinâmica e interativa. Levou-se em consideração o estágio cognitivo das crianças para garantir uma aprendizagem significativa. Através da realização das atividades mediadas pelo computador, o aluno propõe novas estratégias e hipóteses, tem a oportunidade de torna-se um sujeito ativo e participativo do processo de aprendizagem.

Sabendo que a escola não pode deixar de incorporar as novas transformações, cabe ao educador a responsabilidade de buscar e intervir para sistematizar as diversas ferramentas disponíveis, integrando-as como recurso pedagógico a fim de criar condições favoráveis de aprendizagem. Por isso, deverá ter claro qual o paradigma implícito em sua proposta de utilização do computador, para então definir sua prática. 
Contudo, torna-se preponderante que nós, professores, entendamos o grande potencial que as ferramentas tecnológicas podem oferecer a quem ensina e a quem aprende. Em suma, este estudo mostra que aprender e ensinar com o auxílio das TICs, nas relações que se estabelecem com a máquina, professores e alunos, podem produzir, mediante práticas reflexivas e colaborativas, uma nova cultura escolar.

Dessa forma, os softwares podem ser considerados um recurso didático-pedagógico quando se configura uma ferramenta de apoio significativo no complemento dos conteúdos escolares, constituindo-se um recurso motivador tanto para educador quanto para o educando. Estes, quando bem contextualizados, podem se tornar aliados no processo de ensino e aprendizagem, pois desempenham uma dupla função: a lúdica e a didática, de maneira criativa, motivadora e prazerosa. Espera-se, portanto, que o educador, em seu processo de mediador, desenvolva seu trabalho de uma maneira significativa em relação à aprendizagem do educando.

De maneira a dar continuidade ao estudo em diferentes linhas para complementá-lo e enriquecê-lo, propõe-se as seguintes linhas de pesquisa: - O que pensam os professores sobre a implantação e a utilização de novas TIC em sala de aula? - Como a atividade profissional do pedagogo pode ser potencializada pela utilização das novas tecnologias?

\section{REFERÊNCIAS BIBLIOGRÁFICAS}

CONFORTO, Débora. Projetos Pedagógicos: A inclusão na prática educacional. Material elaborado para o PROINESP - Curso de Formação em Serviço de Professores em Informática na Educação Especial, 2007.

FERREIRO, Emília e TEBEROSKI, Ana: Psicogênese da Língua escrita. Ed. Artes Médicas. Porto Alegre. 4.ed.1991.

FERREIRO, Emília. Com Todas as Letras. Ed. Cortez. São Paulo. 8. ed. 2000.

GUIA DE TECNOLOGIAS EDUCACIONAIS 2008 / organização Cláudio

Fernando André. - Brasília: Ministério da Educação, Secretaria de

Educação Básica, 2009. 152 p. Disponível na internet em:

$<$ http://jornalescolar.org.br/portal/images/PDF/guia\%20mec\%20tecnologias\%

20educacionais\%202008.pdf> Acesso em: 29 de julho de2009.

MATTÉ, Volnei Antônio. Metodologia Científica. Material elaborado para o Curso de Especialização - Tecnologias da Informação e da Comunicação Aplicadas à Educação/ EAD- Disciplina: Metodologia Científica- EAD. Santa Maria, 2009.

PRIETO, Lilian Medianeira et al. Uso das Tecnologias Digitais em Atividades

Didáticas nas Séries Iniciais. In: Renote - Revista Novas Tecnologias na Educação. V.3 No.1, 2005. Disponível na internet em:

$<$ http://www.cinted.ufrgs.br/renote/indicegeral-titulo.html\#u> Acesso em 04 de agosto de 2009.

SILVA, Célia M.Onofre. Criança-professor-computador: possibilidades interativas e sociais na sala de aula. In: Revista de Humanidades V.21 №.2 2006: Disponível na internet em:

$<$ http://www.unifor.br/notitia/servlet/newstorm.ns.presentation.NavigationServlet?publi

V. $7 \mathrm{~N}^{\circ}$ 3, dezembro, 2009 


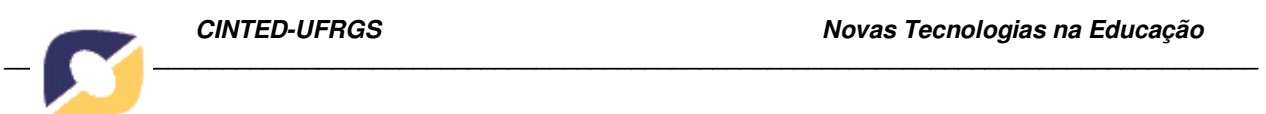

cationCode $=1 \&$ pageCode $=186 \&$ textCode $=4788 \&$ date $=$ currentDate $>$ Acesso em: 04 de agosto de 2009.

TEBEROSKY, Ana. Debater e opinar estimulam a leitura e a escrita. In: Revista Nova Escola. Entrevista dada em Novembro de 2005. Disponível na internet:

$<$ http://revistaescola.abril.com.br/lingua-portuguesa/pratica-pedagogica/debateropinar-estimulam-leitura-escrita-423497.shtml > Acesso em: 25 de agosto de 2009.

VALENTE, José Armando (org). Computadores e conhecimento: repensando a educação. Campinas: NIED/UNICAMP, Gráfica Central da UNICAMP, São Paulo, 1993.

VALENTE, José Armando. O uso inteligente do computador na educação. 1997. Disponível em: <http://www.proinfo.mec.gov.br/upload/biblioteca/215.pdf> Texto publicado na: Pátio - revista pedagógica. Editora Artes Médicas Sul. Ano 1, No 1. Acesso em: 22 de agosto de 2009.

VALENTE, José. A. e FREIRE, Fernanda M. P(org). Aprendendo para a vida: os computadores na sala de aula. São Paulo: Cortez, 2001.

Legislação e Documentos Legais:

BRASIL. Lei no 9394/96 de 20 de dezembro de 1996 — Lei de Diretrizes e Bases da Educação Nacional. Brasília.

BRASIL. Secretaria de Educação Fundamental. Parâmetros Curriculares Nacionais: Introdução aos Parâmetros Curriculares Nacionais. Brasília: MEC/SEF, 1997.

PDE. Plano de Desenvolvimento da Educação, 2008. Disponível na internet em: $<$ http://portal.mec.gov.br/pde> Acesso em: 08 de agosto de 2009.

Endereços Eletrônicos dos Softwares usados:

Tux Paint : <http://tuxpaint.org/download>

Menino Curioso: < http://www.audiogamesbrasil.com/curioso.php>

Atividades Educativas: <http://www.atividadeseducativas.com.br> 